RESIDENT

\& FELLOW

SECTION

Section Editor

Mitchell S.V. Elkind,

MD, MS

Hiroyuki Nodera, MD

Address correspondence and reprint requests to Dr. Hiroyuki

Nodera, Department of

Neurology, Tokushima

University Hospital, 2-50-1

Kuramotocho, Tokushima-City

770-8503, Japan

hnodera@clin.med.tokushima-u.ac.jp

\title{
International Issues: Postgraduate neurologic training in Japan
}

In Japan, postgraduate training in neurology and other medical specialties is undergoing significant change. In the past, Japanese neurologic education and training took place at the local level, with great variability among centers, and trainees had limited knowledge of general medicine before entering specialty training. In 2004, Japan instituted a system whereby all trainees had to complete a 2 -year general training program before entering their specialty of choice. Several challenges remain, however, including an overemphasis on technology over clinical skills and variability among the many training programs available.

OVERVIEW OF THE OLD POSTGRADUATE TRAINING SYSTEM AND ITS RECENT TRANSITION At the age of 18 years, after graduating from high school, students enter a 6-year university course in the faculty of medicine to obtain an M.B. (Bachelor of Medicine) degree. Typically, the first 1-2 years are spent learning premedical general sciences, followed by basic and clinical medical education. Japanese medical students previously decided their ultimate medical specialties at graduation.

Trainees and practicing physicians employed by hospitals receive a base salary determined by their years of experience, not by their specialties or number of procedures. Therefore, income is not the biggest factor for a medical student to decide on a specialty. An exception to this is some specialists, such as practicing cosmetic surgeons, who can charge their procedures without the restriction of universal health insurance.

Immediately after graduation, most trainees selected a department in their own universities and enrolled into rotation assignments at several local hospitals affiliated with their university. There was no prespecified or standard duration of this training. Residents interested in pursuing basic neuroscience curtailed their clinical training program after 2-3 years. On the other hand, residents interested in pursuing clinical neurology stayed longer in the training program (typically 5-6 years).
There were several problems with the old system. The standard medical care provided in the university and affiliated hospitals was similar regardless of the location of the hospital, which reflected the common educational background of the residents at the university hospital, and this may have been skewed from national and international standards. Another problem with the old system was that physicians acquired a limited knowledge and experience, related to only their medical specialty, because of the lack of training in primary care medicine. This overspecialization may be criticized as a poor approach adopted by young doctors to treat a specific disease or organ, but not the patient as a whole person.

In order to solve these problems, in 2004, the Ministry of Health, Labor and Welfare of Japan mandated 2 years of postgraduate medical training in primary care medicine with rotations in all the major specialties. After this more broad-based internship, trainees decide their ultimate medical specialties and become senior residents in their respective specialties.

A nationwide matching system is available only for internship; the selection process for specialty training depends on each individual program, including the number of positions available. This has raised concern that there are varied levels of competence among specialists. Neurology and other specialty residency programs are funded by each hospital individually, and the salary of the residents tends to be low; as a result, the residents often moonlight to support themselves.

\section{CURRENT SYSTEM OF POSTGRADUATE EDU-} CATION IN JAPAN There are approximately 300 accredited training programs in neurology in Japan, which is many more than those offered in the United States. In the current neurology training curriculum, first year neurology residents complete rotation assignments in the inpatient ward to be trained in general neurologic care, and they may receive additional training in related fields such as neurophysiology, neuroradiology, and neuropathology. The senior 
years of residency are individualized according to the interests of the residents. Neurology residents interested in further subspecialty training often pursue basic neuroscience research in the field of interest. Subspecialty fellowship training is available, but is limited to only a handful of institutions such as the National Center of Neurology and Psychiatry in Tokyo.

A local meeting of the neurologic society (The Societas Neurologica Japonica ${ }^{1}$ ) is held $2-4$ times a year. This meeting is a unique educational opportunity and has become a highlight of most residency programs. At the meeting, a resident presents a report of a challenging patient; the presentation includes the differential diagnosis, interpretation of test results, management of the patient, and a review of the literature. The quality of the presentation is considered by many to reflect the quality of medical care provided at each medical center; therefore, extensive preparation is regarded as essential. The entire staff of each hospital attends the resident's rehearsal of the presentation, which often leads to intense and serious criticism of the presentation details. Despite such a harrowing experience before and during the presentation, the procedures used in diagnosis and patient care are clarified by the residents, and the experience is regarded as educational. Often the presenting resident prepares a case report for publication, which provides another educational opportunity.

BOARD CERTIFICATION One of the educational goals of the Japanese neurology residency training program is to pass the neurology board examination. The eligibility criteria to sit for the neurology board examination are as follows: 1) 6 years or more of postgraduate medical training including 3 years in neurology training, 2 years of initial general training, and 1 year of internal medicine training; and 2) board certification in internal medicine. To be eligible for the internal medicine board examination, a resident must complete 2 years of a general medicine rotation plus 1 year of internal medicine training. To sit for the board examination in either internal medicine or neurology, the duration of the training is important and there is no requirement for a minimum number of patients treated or procedures performed. This has raised a significant concern for variability in clinical skills among board-certified physicians, and a stricter system is now considered necessary.

The neurology board examination consists of written and oral components. The written board examination is a half-day test covering a broad range of neurologic topics and includes questions in basic sciences along with different images (such as MRI, pa-

\begin{tabular}{|lrc|}
\hline Table & $\begin{array}{l}\text { Number of MRI and CT machines (units/ } \\
\text { million population) }\end{array}$ & \\
& MRI & CT \\
Japan & 40.1 & 92.6 \\
United States & 26.6 & 32.2 \\
OECD average & 9.8 & 20.6 \\
\hline
\end{tabular}

Data obtained from Health at a Glance 2007: OECD Indicators. ${ }^{2}$

OECD = Organization for Economic Co-operation and Development.

thology, electroencephalography). The applicant is also required to submit 10 discharge summaries, and is questioned in detail on these summaries during the oral examination. Further, at the oral examination, the applicant is asked to perform a neurologic examination on a healthy volunteer. The total passing rate of the neurology board examination is approximately $60-70 \%$.

CHALLENGES This recent change in the postgraduate training system in Japan has raised several issues. First, since there are a large number of training programs (approximately 650), some small programs may have difficulty in providing teaching in neurologic subspecialties. For example, trainees in a hospital that lacks subspecialists may not receive adequate training in subspecialties such as electrodiagnostics, neuropathology, or neuroradiology. The lack of a broad range of subspecialists in the training program is reflected by the fact that the number of faculty physicians in Japanese university hospitals and similar major hospitals is small (mostly below 5; some larger programs exceed 10 , but this is rare) when compared with their American counterparts. Even more significant is the fact that since the pediatric neurology section is usually a part of the pediatric department, the training in pediatric neurology provided to the adult neurology trainees (and vice versa) is often unsatisfactory.

Another problem with this education is the excessive reliance on diagnostic tests. Japan has, by far, the highest number of MRI and CT scanners per capita among industrialized countries (table). ${ }^{2}$ Thus, such imaging tests are easily requested by neurology residents, often before determining the clinical localization and differential diagnosis by obtaining a detailed history and conducting a neurologic examination. This limited approach to evaluation may cause tragic consequences in some instances. For example, this author is aware of a case in which a patient with hypoglycemic coma underwent brain MRI scan before proper treatment with glucose, resulting in irreversible brain damage. There is no instant remedy for 
the problem. However, young trainees might do well to inherit their diagnostic skills from senior neurologists who received neurology training when more limited imaging modalities were available, and when diagnostic and therapeutic judgment depended to an even greater extent on the history and physical examination.

FUTURE AFTER COMPLETING THE RESIDENCY PROGRAM IN JAPAN After the completion of neurology training, some residents take jobs in their training hospitals or other institutions, while others pursue research. The recent success of neurologic re- search in Japan is largely due to the large number of Japanese neurologists pursuing doctoral degrees in neuroscience. However, the new training system with 2 years of general internship may disrupt this trend because of the delay in the start of neurologic training.

\section{REFERENCES}

1. Japanese Society of Neurology (Societas Neurologica Japonica). Available at: http://www.neurology-jp.org/en/ about.html. Accessed January 14, 2009.

2. Health at a glance 2007: OECD indicators. Available at: http://puck.sourceoecd.org/vl=1631204/cl=14/nw=1/ rpsv/health2007/4-7.htm. Accessed January 14, 2009. 


\section{Neurology}

\section{International Issues: Postgraduate neurologic training in Japan \\ Hiroyuki Nodera \\ Neurology 2009;72;e34-e36 \\ DOI 10.1212/01.wnl.0000342477.70435.ef}

This information is current as of February 16, 2009

Updated Information \&

Services

Citations

Subspecialty Collections

Permissions \& Licensing

Reprints including high resolution figures, can be found at:

http://n.neurology.org/content/72/7/e34.full

This article has been cited by 1 HighWire-hosted articles:

http://n.neurology.org/content/72/7/e34.full\#\#otherarticles

This article, along with others on similar topics, appears in the following collection(s):

All Education

http://n.neurology.org/cgi/collection/all_education

Training-international

http://n.neurology.org/cgi/collection/training_international

Information about reproducing this article in parts (figures,tables) or in its entirety can be found online at:

http://www.neurology.org/about/about_the_journal\#permissions

Information about ordering reprints can be found online:

http://n.neurology.org/subscribers/advertise

Neurology ${ }^{\circledR}$ is the official journal of the American Academy of Neurology. Published continuously since 1951, it is now a weekly with 48 issues per year. Copyright. All rights reserved. Print ISSN: 0028-3878. Online ISSN: 1526-632X.

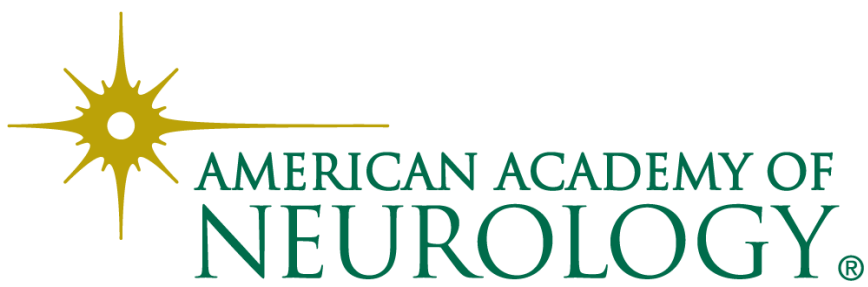

